Microbial Preparations (Probiotics) for the Prevention of Clostridium difficile Infection in Adults and Children: An Individual Patient Data Meta-analysis of 6,851 Participants.

Johnston, BC

http://hdl.handle.net/10026.1/11863

10.1017/ice.2018.84

Infect Control Hosp Epidemiol

Cambridge University Press (CUP)

All content in PEARL is protected by copyright law. Author manuscripts are made available in accordance with publisher policies. Please cite only the published version using the details provided on the item record or document. In the absence of an open licence (e.g. Creative Commons), permissions for further reuse of content should be sought from the publisher or author. 


\title{
Microbial Preparations (Probiotics) for the Prevention of Clostridium difficile Infection in Adults and Children: An Individual Patient Data Meta-analysis of 6,851 Participants
}

\author{
Bradley C. Johnston, PhD $;{ }^{1}$ Lyubov Lytvyn, MSc; ${ }^{2}$ Calvin Ka-Fung Lo, BHSc; ${ }^{3}$ Stephen J. Allen, MD $;{ }^{4}$ Duolao Wang, PhD; ${ }^{4}$ \\ Hania Szajewska, MD; $;^{5}$ Mark Miller, MD $;^{6}$ Stephan Ehrhardt, MD $;{ }^{7}$ John Sampalis, MD; ${ }^{6}$ Deniz G. Duman, MD; ${ }^{8}$ \\ Pietro Pozzoni, MD; ${ }^{9}$ Agostino Colli, MD; ${ }^{9}$ Elisabet Lönnermark, MD; ${ }^{10}$ Christian P. Selinger, MD; ${ }^{11}$ \\ Samford Wong, PhD; ${ }^{12}$ Susan Plummer, MD; ${ }^{13}$ Mary Hickson, PhD $;{ }^{14}$ Ruzha Pancheva, MD, PhD $;{ }^{15}$ Sandra Hirsch, MD; ${ }^{16}$ \\ Bengt Klarin, MD; ${ }^{17}$ Joshua Z Goldenberg, ND; ${ }^{18}$ Li Wang, MD; ${ }^{19,20}$ Lawrence Mbuagbaw, PhD; ${ }^{2, \star}$ Gary Foster, PhD; ${ }^{21}$ \\ Anna Maw, MD; ${ }^{22}$ Behnam Sadeghirad, MPH; ${ }^{2}$ Lehana Thabane, PhD; ${ }^{2}$ Dominik Mertz, $\mathrm{MD}^{2,23}$
}

овјестіvе. To determine whether probiotic prophylaxes reduce the odds of Clostridium difficile infection (CDI) in adults and children. DESIGN. Individual participant data (IPD) meta-analysis of randomized controlled trials (RCTs), adjusting for risk factors.

Methods. We searched 6 databases and 11 grey literature sources from inception to April 2016. We identified 32 RCTs (n=8,713); among them, 18 RCTs provided IPD ( $n=6,851$ participants) comparing probiotic prophylaxis to placebo or no treatment (standard care). One reviewer prepared the IPD, and 2 reviewers extracted data, rated study quality, and graded evidence quality.

RESUlts. Probiotics reduced CDI odds in the unadjusted model ( $\mathrm{n}=6,645$; odds ratio [OR] 0.37; 95\% confidence interval [CI], 0.25-0.55) and the adjusted model $(\mathrm{n}=5,074$; OR, 0.35; 95\% CI, 0.23-0.55). Using 2 or more antibiotics increased the odds of CDI (OR, 2.20; 95\% CI, 1.11-4.37), whereas age, sex, hospitalization status, and high-risk antibiotic exposure did not. Adjusted subgroup analyses suggested that, compared to no probiotics, multispecies probiotics were more beneficial than single-species probiotics, as was using probiotics in clinical settings where the CDI risk is $\geq 5 \%$. Of 18 studies, 14 reported adverse events. In 11 of these 14 studies, the adverse events were retained in the adjusted model. Odds for serious adverse events were similar for both groups in the unadjusted analyses $(n=4,990 ;$ OR, 1.06; 95\% CI, 0.89-1.26) and adjusted analyses $(\mathrm{n}=4,718$; OR, 1.06; $95 \%$ CI, $0.89-1.28)$. Missing outcome data for CDI ranged from $0 \%$ to $25.8 \%$. Our analyses were robust to a sensitivity analysis for missingness.

CONCLUSIONs. Moderate quality (ie, certainty) evidence suggests that probiotic prophylaxis may be a useful and safe CDI prevention strategy, particularly among participants taking 2 or more antibiotics and in hospital settings where the risk of CDI is $\geq 5 \%$.

Trial REgistration. PROSPERO 2015 identifier: CRD42015015701

Infect Control Hosp Epidemiol 2018;39:771-781

Clostridium difficile infection (CDI) is the leading cause of hospital-associated infectious diarrhea. ${ }^{1}$ Diarrhea is the most

common presentation; however, CDI may result in more serious sequelae including pseudomembranous colitis, toxic

Affiliations: 1. Department of Community Health and Epidemiology, Faculty of Medicine, Dalhousie University, Halifax, Nova Scotia, Canada; 2. Department of Clinical Epidemiology and Biostatistics, McMaster University, Hamilton, Ontario, Canada; 3. McMaster University, Hamilton, Ontario, Canada; 4. Department of Clinical Sciences, Liverpool School of Tropical Medicine, Liverpool, United Kingdom; 5. Department of Pediatrics, The Medical University of Warsaw, Warsaw, Poland; 6. McGill University, Montreal, Québec, Canada; 7. Department of Epidemiology, The Johns Hopkins Bloomberg School of Public Health, Baltimore, Maryland, United States; 8. Department of Gastroenterology, Marmara University, School of Medicine, Istanbul, Turkey; 9. Department of Internal Medicine, A Manzoni Hospital AO Provincia di Lecco, Lecco, Italy; 10. Department of Infectious Diseases, Gothenburg University, Göteborg, Sweden; 11. Department of Gastroenterology, St James University Hospital, Leeds, United Kingdom; 12. National Spinal Injuries Center, Stoke Mandeville Hospital, Aylesbury, United Kingdom; 13. Research and Development Department, Cultech Ltd, Port Talbot, United Kingdom; 14. Nutrition and Dietetic Research Group, Plymouth University, United Kingdom; 15. Department of Hygiene, Medical University, Varna, Bulgaria; 16. Instituto de Nutrición y Tecnología de los Alimentos, University of Chile, Santiago, Chile; 17. Department of Anesthesiology and Intensive Care, Lund University Hospital, Lund, Sweden; 18. Bastyr University Research Institute, Kenmore, Washington, United States; 19. Michael G. DeGroote Institute for Pain Research and Care, McMaster University, Hamilton, Ontario, Canada; 20. Department of Anesthesia, McMaster University, Hamilton, Ontario, Canada; 21. St Joseph's Healthcare Hamilton, Hamilton, Ontario, Canada; 22. Division of Hospital Medicine, Department of Medicine, University of Colorado, Denver, Colorado, United States; 23. Department of Medicine, McMaster University, Hamilton, Ontario, Canada.

${ }^{*}$ Author name has been corrected since original publication. A corrigendum notice detailing this change was also published (DOI: 10.1017/ice.2018.120).

Received August 29, 2017; accepted March 13, 2018; electronically published April 26, 2018

(C) 2018 by The Society for Healthcare Epidemiology of America. All rights reserved. 0899-823X/2018/3907-0002. DOI: 10.1017/ice.2018.84 
megacolon, and death, ${ }^{2,3}$ and mortality ranges from $5 \%$ to $10 \%{ }^{3}$ Frequent recurrence, affecting $\sim 20 \%$ of treated participants, is particularly challenging for CDI management. ${ }^{4}$ Most CDI cases occur in higher-income countries, ${ }^{5}$ but data from middle- and low-income countries are lacking. Surveillance data suggest that the incidence density ranges between 2.45 and 7.5 per 10,000 patient days or between 9 and 80 per 10,000 patient admissions. ${ }^{2,6-8}$ An individual patient's risk of developing CDI differs based on numerous host and environmental factors, ${ }^{2,6,9,10}$ most importantly antibiotic exposure, which is thought to disrupt the intestinal microbiota, allowing $C$. difficile to proliferate. ${ }^{6}$

Probiotics, defined as live microorganisms that, when administered in adequate amounts, may confer a health benefit on the host, are a potential CDI prevention strategy. ${ }^{11}$ A 2013 Cochrane meta-analysis of 23 randomized controlled trials (RCTs) demonstrated a 64\% decrease (95\% confidence interval [CI] , 49\%-73\%) in CDI incidence with probiotic prophylaxis. ${ }^{12}$ The results of a subsequent large $\operatorname{RCT}(n=2,941)$ were indeterminate; however, CDI events were less frequent than anticipated. An updated aggregate data meta-analysis incorporating the study showed that the beneficial effect of the probiotic remained. ${ }^{13}$ A recent review of clinical practice guidelines on CDI prevention ${ }^{14}$ found that recommendations mainly revolved around core strategies (eg, education of healthcare staff on CDI, patient isolation, antimicrobial stewardship, and utilization of disinfectants), but none recommend probiotics for prophylaxis. ${ }^{15-19}$ Guidelines cited concerns regarding insufficient evidence, ${ }^{17,20}$ too much weight given to studies with high baseline CDI risk, ${ }^{16}$ and safety concerns. ${ }^{16,20}$

To address some of these concerns and to further investigate the effectiveness and safety of probiotics on populations and interventions with varying characteristics, we conducted an individual participant data (IPD) meta-analysis. Our objective was to determine whether adding probiotics to an antibiotic regimen reduces the incidence of CDI among children and adults, when adjusting for age, sex, hospitalization status, the number of antibiotics taken, and the administration of high-risk antibiotics.

\section{METHODS}

We registered the protocol for this IPD meta-analysis in the PROSPERO registry in January $2015 .^{21}$

\section{Searches}

We considered all studies deemed eligible in a previous comprehensive systematic review on probiotics for the prevention of CDI (Appendix Methods 1), ${ }^{12}$ and we updated the search on April 11, 2016 (Appendix Tables 1 and 2).

\section{Study Selection}

Two reviewers independently screened titles, abstracts, and full-text articles for eligibility and resolved differences through consensus. We included RCTs with children $(0$ to $<18$ years $)$ or adults administered antibiotics (ie, any reason or duration) with concomitant probiotics (ie, any dose, species, strain, or duration), compared to placebo, alternative prophylaxis, or no treatment (standard care), and that reported CDI as an outcome. The latter was our primary outcome, defined as either diarrhea with laboratory confirmation of $C$. difficile, presence of pseudomembranes on sigmoidoscopy or colonoscopy, histological diagnosis of $C$. difficile, or diagnosis of toxic megacolon. ${ }^{22}$ Our secondary outcome was the incidence of serious adverse events (SAEs).

\section{Data Extraction and Quality Assessment}

We contacted the authors of all eligible studies and requested ethics-approved, deidentified data including participants' allocated treatment, age, length of hospital stay, CDI history, antibiotics given, probiotics given, presence of diarrhea, CDI diagnosis, and SAEs. We also requested any information on missing outcome data, such as participants lost to follow up and participants who had diarrhea but no $C$. difficile test.

Reviewer pairs (B.C.J., J.G., L.L.) independently assessed risk of bias based on the Cochrane Handbook for Systematic Reviews of Interventions. ${ }^{23}$ For studies from the previous review, we used the previous assessment, ${ }^{12}$ with 6 modifications (Appendix Methods 2). For the overall certainty in estimates for each outcome, we used Grading of Recommendations, Assessment, Development and Evaluation (GRADE), independently and in duplicate. ${ }^{24}$ Publication bias was evaluated with a funnel plot. ${ }^{25}$

\section{Data Synthesis and Analysis}

We pooled IPD across trials and analyzed it using a generalized linear mixed model using the SAS GLIMMIX procedure using SAS/STAT version 9.4 software (SAS Institute, Cary, NC) and calculated the odds ratio (OR) and 95\% CIs. We considered the study level as a random effect and the participant variables as fixed. For our adjusted analysis, based on known CDI risk factors, variables available across datasets, and data provided by authors, we developed a model adjusting for 5 variables: age (years), ${ }^{10}$ sex, hospitalization status, use of multiple antibiotics, and exposure to high-risk antibiotics (third- and fourth-generation cephalosporins, lincosamides, and fluoroquinolones). ${ }^{6}$ Only hospitalized participants had SAEs; thus, we did not adjust for this variable.

Statistical heterogeneity was evaluated using the $\mathrm{I}^{2}$ value, where an $\mathrm{I}^{2}$ value of 0 to $40 \%$ represented low heterogeneity and an $\mathrm{I}^{2}$ value of $30 \%-60 \%$ represented moderate heterogeneity. ${ }^{26}$ We used Review Manager version 5.3 software (Copenhagen, Denmark) for aggregate data meta-analyses and funnel plots. We used SPSS version 20 software (IBM Armonk, NY) and SAS/ STAT version 9.4 software for data cleaning and analysis, respectively. We used Stata version 13 software (StataCorp, College Station, TX) to graph the IPD meta-analysis forest plots. Given the low event rate for CDI and SAEs $(<10 \%)$, the OR approximates the relative risk (RR). Thus, we reported relative risk reduction (RRR) for ease of interpretation. 


\section{Subgroup Analyses}

We conducted 4 a priori subgroup analyses. First, as an approximation of baseline CDI incidence, we examined studies with low $(<5 \%)$ control-group event rates versus those with rates $\geq 5 \%$. ${ }^{16}$ Second, we compared no probiotics (ie, control group) to single-species probiotics. Third, we compared no probiotics to multispecies or multistrain probiotics. ${ }^{13}$ Fourth, we looked at probiotic dose, where participants in the control group had zero colony-forming units (CFU) per day (ie, control group), and we examined the effect of increasing the dose by 1 billion CFU per day in the intervention group. ${ }^{27}$

\section{Sensitivity Analyses}

We conducted 4 a priori sensitivity analyses on our primary outcome. First, we compared the unadjusted analysis (18 studies, $n=6,645)$ with the pooled estimate of effect based on aggregate data ( 18 studies, $n=6,447$ ). Second, we compared the adjusted analysis ( 13 studies; $n=5,074$ ) with the pooled estimate of effect based on aggregate data (13 studies; $n=5,341$ ). Third, for the adjusted analysis of CDI, we categorized age (infants 0 to $<1$ year, children 1 to $<18$ years, adults 18 to $<65$ years, older adults $65+$ years) to determine whether age groups are more predictive of CDI than continuous linear age. We discerned infants from children because before 1 year of age, $C$. difficile colonization is common and does not reflect CDI. ${ }^{28}$ Fourth, for the adjusted analysis, we accounted for clustering using generalized estimation equations (GEE) using the SAS GENMOD procedure.

\section{Handling Missing Participant Data}

Participants with no reported outcome for CDI were considered as having missing outcome data. If participants with missing CDI outcome data had reported no diarrhea, we assumed they did not have CDI. If participants had reported diarrhea but no CDI test result, we considered this missing outcome data. We conducted a sensitivity analysis using the PROC MI procedure in SAS to impute missing data to create 5 imputed data sets. We examined the effect of multiple imputation on regression estimates using PROC MIANALYZE.

\section{RES ULTS}

\section{Data Selection and Data Obtained}

Of 2,021 articles, we obtained IPD from 18 of 32 confirmed eligible trials ${ }^{29-46}$ with IPD for 6,851 of 8,713 participants (78.6\% of all available data). Among our sample of 6,851, participants had $120 \mathrm{CDI}$ events and 613 SAEs (Table 1). There were 11 formulations of probiotics given, with doses ranging from 0.1 to 900 billion CFUs per day. Most studies (88.9\%) used placebo as a control and were conducted in adult hospitalized participants (72.2\%) (Table 1). The proportion of participants on high risk antibiotics at any given time ranged from $0 \%{ }^{30,31}$ to $85.4 \%{ }^{44}$ (Table 2). For the outcome CDI, 2 studies
(11.1\%) did not report participant level data on antibiotics taken, ${ }^{38,39}$ and 3 studies (16.7\%) did not report age. ${ }^{36,37,43}$ Thus, 1,777 of 6,851 participants (26\%) were excluded from the adjusted CDI model $(n=5,074)$. The length of hospital stay and CDI history were not available for most datasets and were not included in the model. In terms of missing outcome data for CDI, study results ranged from zero ${ }^{29,32,35,38,40,41,44-46}$ to $25.8 \%{ }^{33}$ For our secondary outcome, 14 of 18 studies provided IPD for SAEs. ${ }^{29-33,35-38,40,41,44-46}$ Our adjusted model was based on 11 of these 14 studies because 3 studies did not report age (16.7\%). ${ }^{36,37,43}$ Thus, 272 of 4,990 participants (5.5\%) were excluded from this model $(\mathrm{n}=4,718)$.

\section{Risk of Bias Assessment}

For the primary outcome CDI, 4 studies were at high risk of bias for incomplete outcome data because $>10 \%$ of participants either had no data provided or had diarrhea but no CDI test $^{30,31,33,39}$ (Appendix Figure 1). Another study was at high risk of bias for blinding of participants and personnel along with blinding for outcome assessment. ${ }^{42}$ For SAEs, 1 study was at high risk of bias for incomplete outcome data because authors reported SAEs but did not provide the data. ${ }^{34} \mathrm{We}$ identified 2 studies that were at high risk of bias for blinding both of participants and personnel and of outcome data. ${ }^{30,42}$ Overall, for both CDI and SAEs, 2 studies were at high risk for selective reporting ${ }^{30,34}$ and 5 studies were at high risk of other bias for potential conflict of interest due to industry funding. ${ }^{35-38,45}$

There was no suspected publication bias for CDI among the included studies, which was similar for all eligible studies and studies with data available (Appendix Figure 2). (Figure 1)

\section{Primary Outcome: Clostridium difficile Infection}

Of the 18 studies reporting on CDI outcomes, 38 of 3,384 of cases (1.1\%) were in the intervention group, and 82 of 3,262 (2.5\%) were in the control group (Table 2). Probiotic prophylaxis reduced the unadjusted odds of $\mathrm{CDI}$ (OR, 0.37; 95\% CI, $0.25-0.55 ; P<.0001 ; \mathrm{n}=6,645$; Figure 2 ), similar to the pooled estimate for the 14 studies for which IPD was not obtained (OR, 0.30; 95\% CI, 0.19-0.47; $P<.0001 ; \mathrm{n}=2,266$; Appendix Figure 3). Of the 13 studies included in the adjusted model, probiotics significantly reduced the CDI $(\mathrm{OR}, 0.35 ; 95 \% \mathrm{CI}, 0.23-0.55$; $P<.0001 ; \mathrm{n}=5,074$; Figure 2). The use of 2 or more antibiotics significantly increased the risk of CDI (OR, 2.20; 95\% CI, $1.11-4.37 ; P=.0243)$, whereas age, sex, hospitalization status, and high-risk antibiotic exposure did not.

Multiple imputation sensitivity analysis provided similar regression estimates to the adjusted analysis (OR, 0.37; 95\% CI, 0.25-0.56; $P<.001)$.

\section{Subgroup Analyses}

A control group event rate of $\geq 5 \%$ was significantly associated with CDI in the adjusted model (OR, 16.33; 95\% CI, 7.7934.26; $P<.0001 ; \mathrm{n}=5074$ ) (Figure 2 ) and had significant 
TA B LE 1. Characteristics of Included Studies

\begin{tabular}{|c|c|c|c|c|c|c|c|c|c|c|c|c|c|}
\hline \multirow[b]{2}{*}{ Study } & \multirow[b]{2}{*}{ Probiotic Group } & \multirow{2}{*}{$\begin{array}{l}\text { Dose, } \\
\text { Billion } \\
\text { CFU/d }\end{array}$} & \multirow{2}{*}{$\begin{array}{l}\text { Control } \\
\text { Group }\end{array}$} & \multicolumn{3}{|c|}{$\begin{array}{l}\text { Probiotics Group } \\
\qquad(\mathrm{N}=3,482)^{\mathrm{a}}\end{array}$} & \multicolumn{3}{|c|}{$\begin{array}{l}\text { Control Group } \\
(\mathrm{N}=3,369)\end{array}$} & \multirow{2}{*}{$\begin{array}{l}\text { Inpatient, } \\
\%\end{array}$} & \multirow{2}{*}{$\begin{array}{c}\text { Age, } \\
\text { Mean y (SD) }\end{array}$} & \multirow{2}{*}{$\begin{array}{l}\text { Sex, } \% \\
\text { Male }\end{array}$} & \multirow{2}{*}{$\begin{array}{c}\text { High-Risk } \\
\text { Antibiotics, } \%{ }^{\mathrm{b}}\end{array}$} \\
\hline & & & & $\mathrm{n}$ & CDI & SAE & $\mathrm{n}$ & CDI & SAE & & & & \\
\hline Allen et al, $2013^{39}$ & $\begin{array}{l}\text { L. acidophilus CUL60, CUL21, } \\
\text { B. bifidum CUL20, } \\
\text { B. lactis CUL34 }\end{array}$ & 60 & $\mathrm{P}$ & 1,492 & 12 & 292 & 1,489 & 17 & 280 & 100 & $77.8(8.1)$ & 50.8 & 13.8 \\
\hline Bravo et al, $2008^{29}$ & S. boulardii & 10.2 & $\mathrm{P}$ & 41 & 0 & 0 & 45 & 0 & 0 & 0 & $50.4(19.1)$ & 23.3 & 0 \\
\hline Duman et al, $2005^{28}$ & S. boulardii & 10 & SC & 204 & 0 & 0 & 185 & 1 & 0 & 0 & $45.2(13.4)$ & 51.3 & 0 \\
\hline Ehrhardt et al, $2016^{42}$ & S. boulardii & 9 & $\mathrm{P}$ & 246 & 2 & 7 & 231 & 2 & 3 & 100 & $58.4(17.2)$ & 56.4 & 8.9 \\
\hline Gao et al, $2010^{27}$ & $\begin{array}{l}\text { L. acidophilus CL1285, } \\
\text { L. casei LBC80R }\end{array}$ & $50 ; 100$ & $\mathrm{P}$ & 170 & 9 & 0 & 83 & 20 & 0 & 100 & $59.6(6.3)$ & 51.8 & 29.2 \\
\hline Georgieva et al, $2015^{41}$ & L. reuteri DSM17938 & 0.10 & $\mathrm{P}$ & 49 & 0 & $\cdots$ & 48 & 0 & $\ldots$ & 100 & $\ldots$ & $\ldots$ & 45.8 \\
\hline Hickson et al, $2007^{32}$ & $\begin{array}{l}\text { L. casei imunitass DN-114 001, } \\
\text { L. bulgaris, S. thermophiles }\end{array}$ & 40.74 & $\mathrm{P}$ & 69 & 0 & $\cdots$ & 66 & 9 & $\ldots$ & 100 & $73.8(10.7)$ & 45.9 & 19.3 \\
\hline Klarin et al, $2008^{33}$ & L. plantarum $299 \mathrm{v}$ & 80 & $\mathrm{P}$ & 19 & 0 & 2 & 22 & 1 & 2 & 100 & $60.8(17.2)$ & 68.3 & 48.8 \\
\hline Kotowska et al, $2005^{30}$ & S. boulardii & 30 & $\mathrm{P}$ & 119 & 3 & 0 & 127 & 10 & 0 & 23.2 & $3.8(1.7-7.2)^{\mathrm{c}} \ddagger$ & 43.1 & 1.6 \\
\hline Lonnermark et al, $2010^{43}$ & L. plantarum 299v & 100 & $\mathrm{P}$ & 81 & 0 & 0 & 82 & 0 & 0 & 54.6 & $47.7(47.9)$ & 44.2 & 24.5 \\
\hline Miller et al, $2008^{34}$ & L. rhamnosus GG & 20 & $\mathrm{P}$ & 96 & 0 & 7 & 91 & 2 & 4 & 100 & $\ldots$ & 50.0 & 62.1 \\
\hline Miller et al, $2008^{35}$ & L. rhamnosus GG & 60 & $\mathrm{P}$ & 158 & 2 & 4 & 158 & 0 & $\ldots$ & 100 & $\ldots$ & 47.5 & 23.0 \\
\hline Plummer et al, $2004^{36}$ & L. acidophilus, B. bifidum & 20 & $\mathrm{P}$ & 69 & 2 & 0 & 69 & 6 & 0 & 100 & $62.2(19.0)$ & 53.6 & $\ldots$ \\
\hline Pozzoni et al, $2012^{31}$ & S. boulardii & 10 & $\mathrm{P}$ & 141 & 3 & 0 & 134 & 2 & 0 & 100 & $79.2(9.8)$ & 49.8 & 76.7 \\
\hline Psaradellis et al, $2010^{37}$ & $\begin{array}{l}\text { L. acidophilus CL1285, } \\
\text { L. casei LBC } 80 \mathrm{R}\end{array}$ & 50 & $\mathrm{P}$ & 216 & 2 & $\ldots$ & 221 & 4 & $\ldots$ & 100 & $62.1(17.0)$ & 49.0 & $\ldots$ \\
\hline Ruszczynski et al, $2008^{44}$ & $\begin{array}{l}\text { L. rhamnosus ( } 2593 \text { Pen, } 2594 \\
\text { E/N, } 2595 \text { Oxy) }\end{array}$ & 20 & $\mathrm{P}$ & 120 & 3 & 0 & 120 & 7 & 0 & 54.2 & $3.6(1.5-6.6)^{\mathrm{c}}$ & 54.0 & 9.6 \\
\hline Selinger et al, $2013^{38}$ & VSL\#3 ${ }^{\mathrm{d}}$ & 900 & $\mathrm{P}$ & 116 & 0 & 6 & 112 & 0 & 6 & 100 & $57.3(18.0)$ & 52.6 & 11.0 \\
\hline Wong, $2014^{40}$ & L. casei Shirota & 6.5 & SC & 76 & 0 & $\ldots$ & 86 & 1 & $\ldots$ & 100 & $50.2(19.1)$ & 80.5 & 85.4 \\
\hline
\end{tabular}

NOTE. B, Bifidobacterium; CDI, Clostridium difficile infection; CFU, colony-forming units; d, day; L, Lactobacillus; P, placebo; SAE, serious adverse events; SD, standard deviation; SC, standard care.

${ }^{\mathrm{a}}$ The timing of administration and the duration of probiotics ranged from providing probiotics for the duration of antibiotic exposure and up to $7 \mathrm{~d}$ following completion of antibiotics. Timing of administration ranged from immediately when starting antibiotics and up to $7 \mathrm{~d}$ following antibiotics.

${ }^{\mathrm{b}}$ High-risk antibiotics were third- and fourth-generation cephalosporins, lincosamides, and fluoroquinolones.

${ }^{\mathrm{c}}$ Median and interquartile range.

${ }^{\mathrm{d}}$ B. breve, B. longum, B. infantis, L. acidophilus, L. plantarum, L. paracasei, L. bulgaricus, and S. thermophiles. 
T A B LE 2. Summary Data From Trials Providing Individual Patient Data

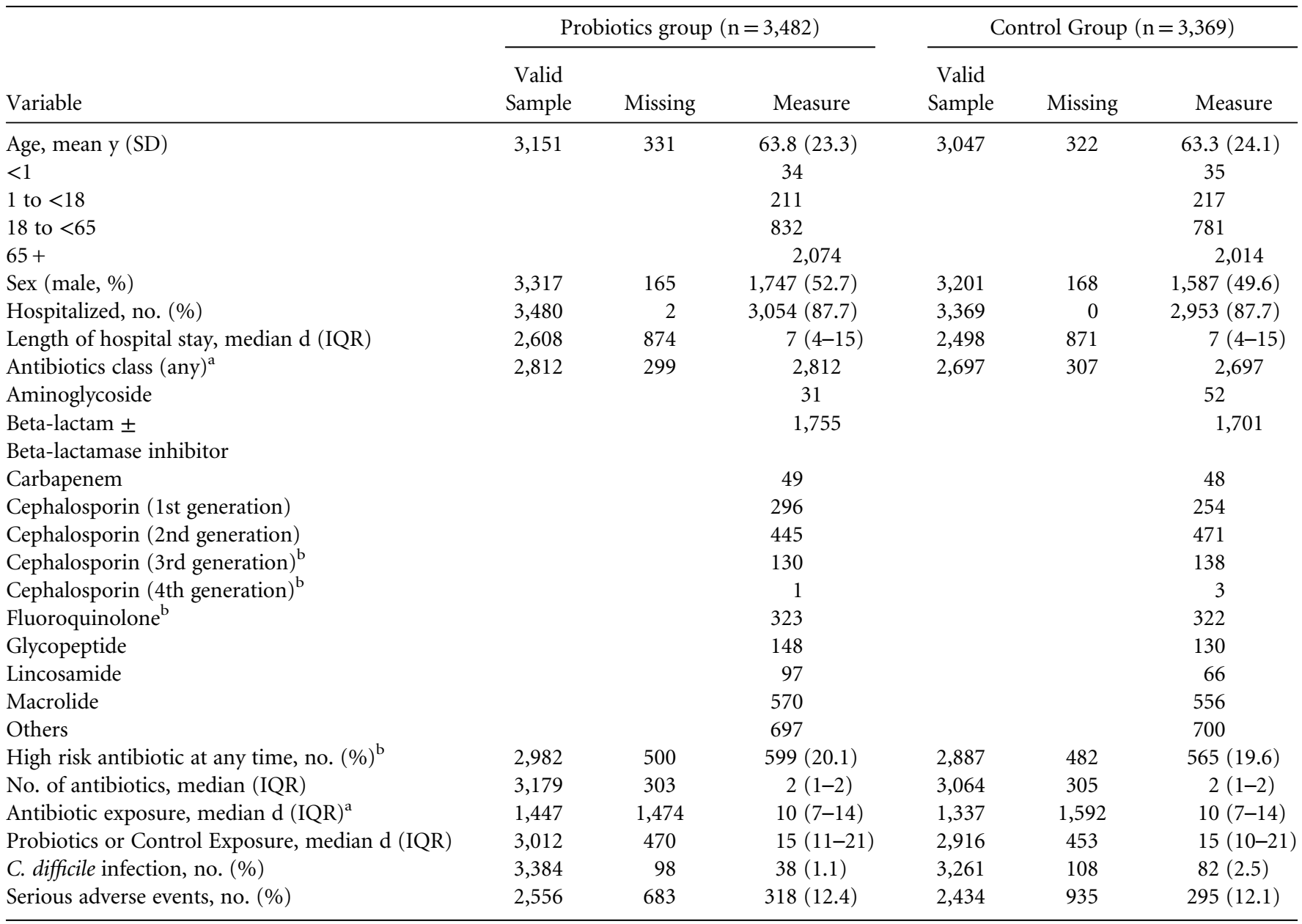

${ }^{a}$ Values for antibiotic class and median, IQR for antibiotic exposure were computed based on studies who had these measures available within data (43-45 were not included).

${ }^{\mathrm{b}}$ High-risk antibiotics were considered 3rd- and 4th-generation cephalosporins, lincosamides, and fluoroquinolones.

interaction with the treatment effect $(P=.007)$. Compared to no probiotics, multispecies probiotics (OR, $0.33 ; 95 \% \mathrm{CI}$, $0.20-0.56 ; \quad P<.0001 ; \mathrm{n}=5,074$ ) (Figure 2 ) significantly reduced $\mathrm{CDI}$, whereas the effect of single-species probiotics was not statistically significant (OR, $0.41 ; 95 \% \mathrm{CI}, 0.17-1.00$; $P=.051 ; \mathrm{n}=5,074$ ) (Figure 2). Compared to no probiotics, a 1 billion CFU per day increase in dose did not significantly reduce CDI risk (OR, 0.99; 95\% CI, 0.99-1.00; $P=.108$; $\mathrm{n}=5,074$ ) (Figure 2).

Post hoc, we conducted a subgroup analysis of 5 trials using S. boulardii $(\mathrm{n}=1,473)$, the probiotic most commonly used among RCTs for CDI prevention, and compared it with trials using other strains $(n=5,381)$. We found no significant difference (OR, 0.86; 95\% CI, 0.10-7.04) (Figure 2).

\section{Sensitivity Analyses}

When treating age as a categorical variable in the multivariate analysis, the effect of probiotics remained similar (OR, 0.35;
95\% CI, 0.22-0.55; $P<.0001$ ) (Figure 2). In a post hoc analysis, we removed infants $<1$ years of age, which resulted in a similar summary estimate (OR, 0.37; 95\% CI, 0.23-0.59; $P<.0001)$ (Figure 2). Results remained similar for the 18 studies in the unadjusted model regarding random-effects aggregate-data meta-analysis ( $\mathrm{n}=6,447$ participants; $\mathrm{OR}, 0.45$; 95\% CI, 0.30-0.68; $\left.P<.0001 ; \mathrm{I}^{2}=8 \%\right)$, for the 13 studies included in the adjusted model $(\mathrm{n}=5,341$ participants; OR, $\left.0.42 ; 95 \% \mathrm{CI}, 0.24-0.72 ; P=.002 ; \mathrm{I}^{2}=21 \%\right)$, and when using GEE for the adjusted analysis (OR, 0.47; 95\% CI, 0.29-0.76; $P=.0022$ ) (Figure 2).

\section{Secondary Outcome: Serious Adverse Events}

Of the 14 studies reporting on the incidence of SAEs, 318 of 2,556 cases $(12.4 \%)$ were in the intervention group and 295 of 2,434 cases $(12.1 \%)$ were in the control group (Table 1). There was no significant difference between groups (OR 1.06; 95\% CI, $0.89-1.26 ; P=.536$ ) (Figure 3 ). There were no cases of 

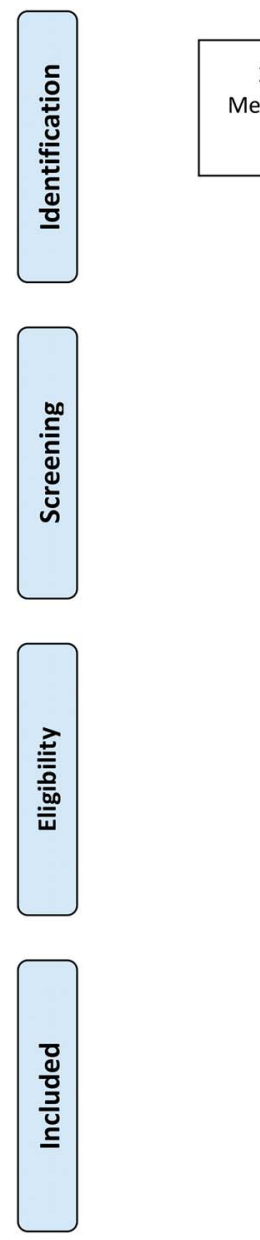

2202 studies identified through AMED and Web of Science

426 studies identified through 11 grey literature sources, as well as contact with probiotic manufacturers

012 titles and abstracts reviewed after removal of duplicates

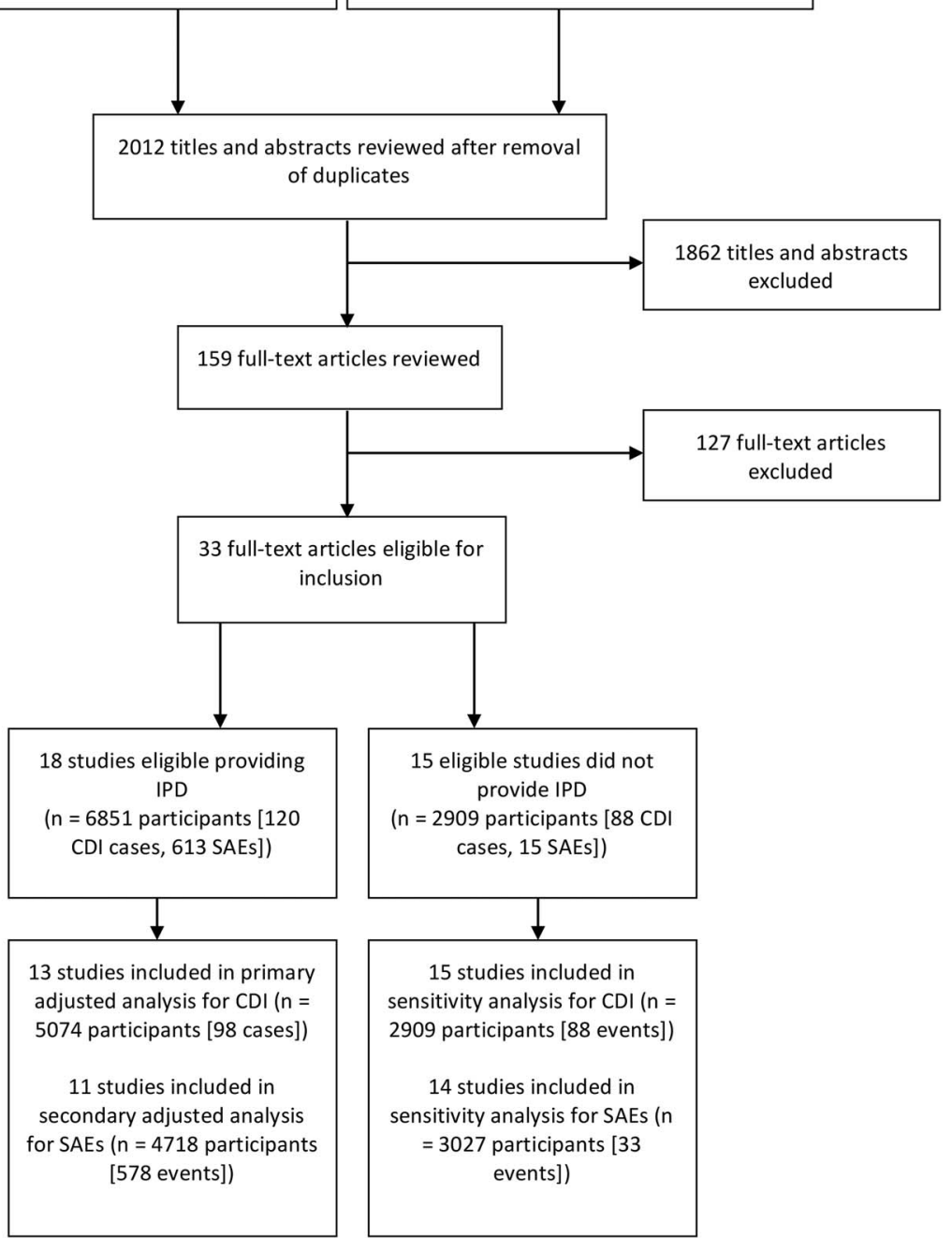

FIGURE 1. Flow of eligible studies providing and not providing individual patient data.

bacteremia or fungemia, and none of the SAEs were deemed attributable to probiotics, based on published findings and correspondence with investigators. Similarly, there were no differences among the 11 studies with data available for the adjusted model (OR, 1.06; 95\% CI, 0.89-1.28; $P=.503$ ) (Figure 3). Increasing age (OR, 1.03; 95\% CI, 1.02-1.04; $P<.0001)$, multiple antibiotic usage (OR, 1.60; 95\% CI, $1.25-$ 2.05; $P=.0002)$, and being treated with high-risk antibiotics (OR, 1.36; 95\% CI, 1.06-1.74; $P=.015$ ) were significantly associated with SAEs, whereas sex was not (Figure 3).

\section{I S C U S S I O N}

Our IPD meta-analysis of 18 trials with data on 6,851 participants found that probiotics reduced the risk of CDI by two-thirds. The risk of SAEs was not significantly different between probiotics and control groups. Importantly, none of the SAEs were attributable to probiotics. The quality (certainty) in the effect estimates for CDI was moderate, downgraded due to a low number of events, while for SAEs the certainty was moderate, downgraded for risk of publication bias (Table 3).

Our results corroborate the findings in a previous aggregatedata meta-analysis. ${ }^{12,47}$ Recent clinical practice guidelines currently do not recommend probiotic prophylaxis, even though probiotics have the highest quality evidence among cited prophylactic therapies, including antibiotic stewardship, hypochlorite solutions, and bundle strategies. ${ }^{14}$

Some suggest that probiotics are most likely to be of benefit in high CDI incidence settings. ${ }^{48,49}$ Data on disease pressure were not available; thus, we approximated the baseline CDI risk using the control group event rates of individual trials. 
Odds Ratio $(95 \% \mathrm{Cl})$

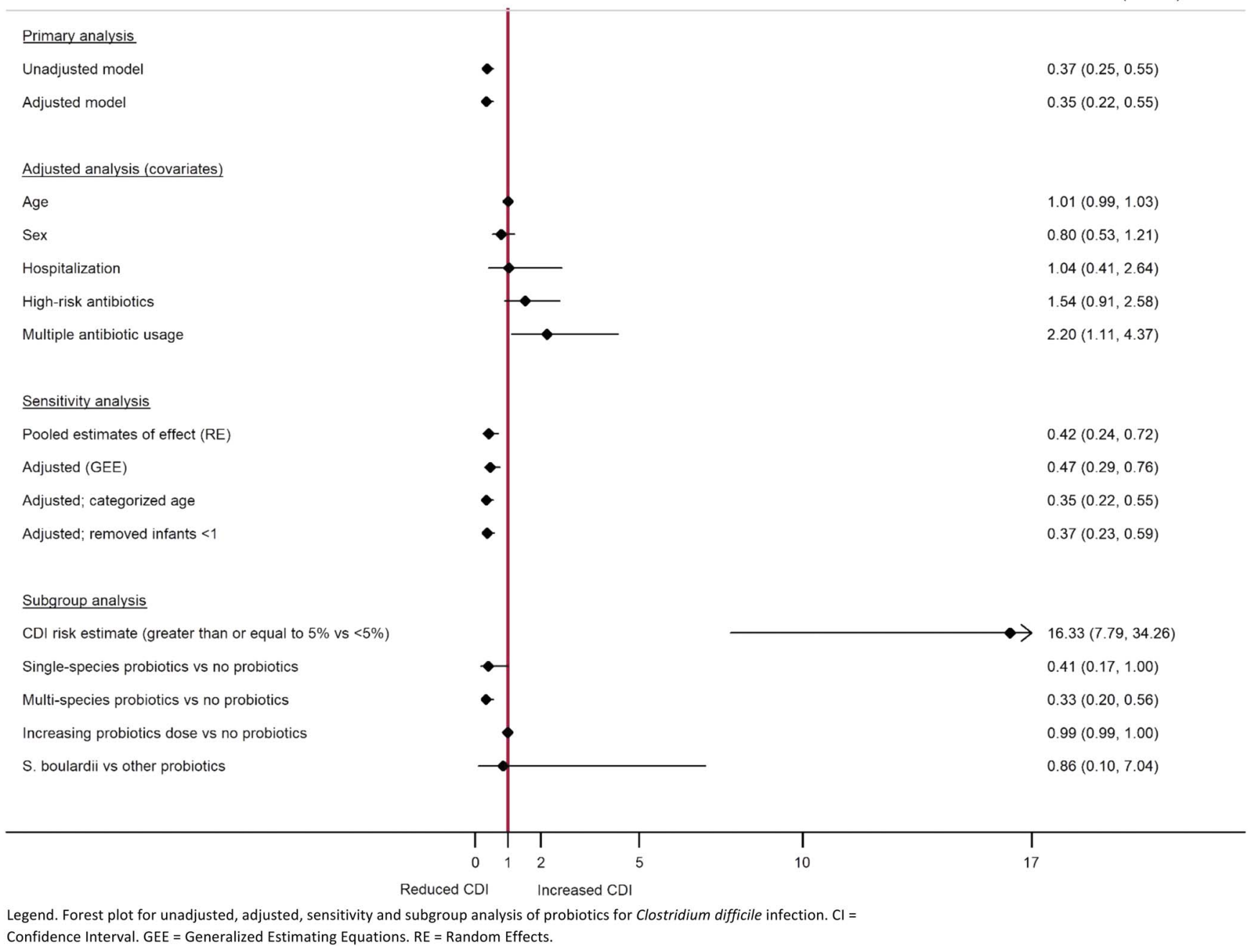

FIGURE 2. Incidence of Clostridium difficile infection.

This analysis suggested that CDI incidence $\geq 5 \%$ interacts with the overall group effect, suggesting that probiotics may be more effective when the baseline CDI risk is moderate to high. Considering the absolute risk reduction (ARR) and corresponding number needed to treat (NNT), if the baseline CDI risk is $1.6 \%$ (median of all studies), the observed effect (OR, 0.35 ) corresponds to an ARR of $\sim 1.0 \%$ and an NNT of 96. Using the same effect estimate, given the mean baseline, CDI risk across all studies is $4.34 \%$, and the ARR will be $2.8 \%$ (NNT, 35).

Combining different probiotic species and strains in metaanalyses is a contentious issue. Some suggested that pooling different probiotic agents is problematic, ${ }^{50}$ while others suggested that pooling probiotics and subsequently assessing any differences using a priori subgroup analysis based on species, strain, and dose is in accordance with standard meta-analysis methods. ${ }^{12}$ As with previous aggregate-data meta-analyses, we found no significant difference between species or strains, suggesting that specific effects based on the type of probiotic may not be an important factor to consider when choosing a probiotic. Instead, it is probably more important to consider the quality of the product and credibility of the manufacturer ${ }^{51}$ and to use a product that has been investigated in RCTs, particularly a multistrain product given our findings. However, as is typical of subgroup assessments, our analysis is likely underpowered. For example, we rated downward for precision for each of our outcomes. For single species and multispecies probiotics, our data suggest that while both reduce CDI compared to no probiotics, multispecies probiotics demonstrated a statistically significant treatment effect compared to no probiotics, whereas single-strain probiotics did not. One hypothesis is that multiple species may have an additive effect or may be associated with a higher dose. Among studies of multistrain probiotics, ${ }^{29,34,38-41,46}$ the daily median value was 50 billion CFU per day; in studies with single-strain probiotics, ${ }^{30-33,35-37,42-45}$ the daily median value was 15.6 billion CFU per day. However, in exploring the impact of dose response, we found no statistically significant trend. Failure to 


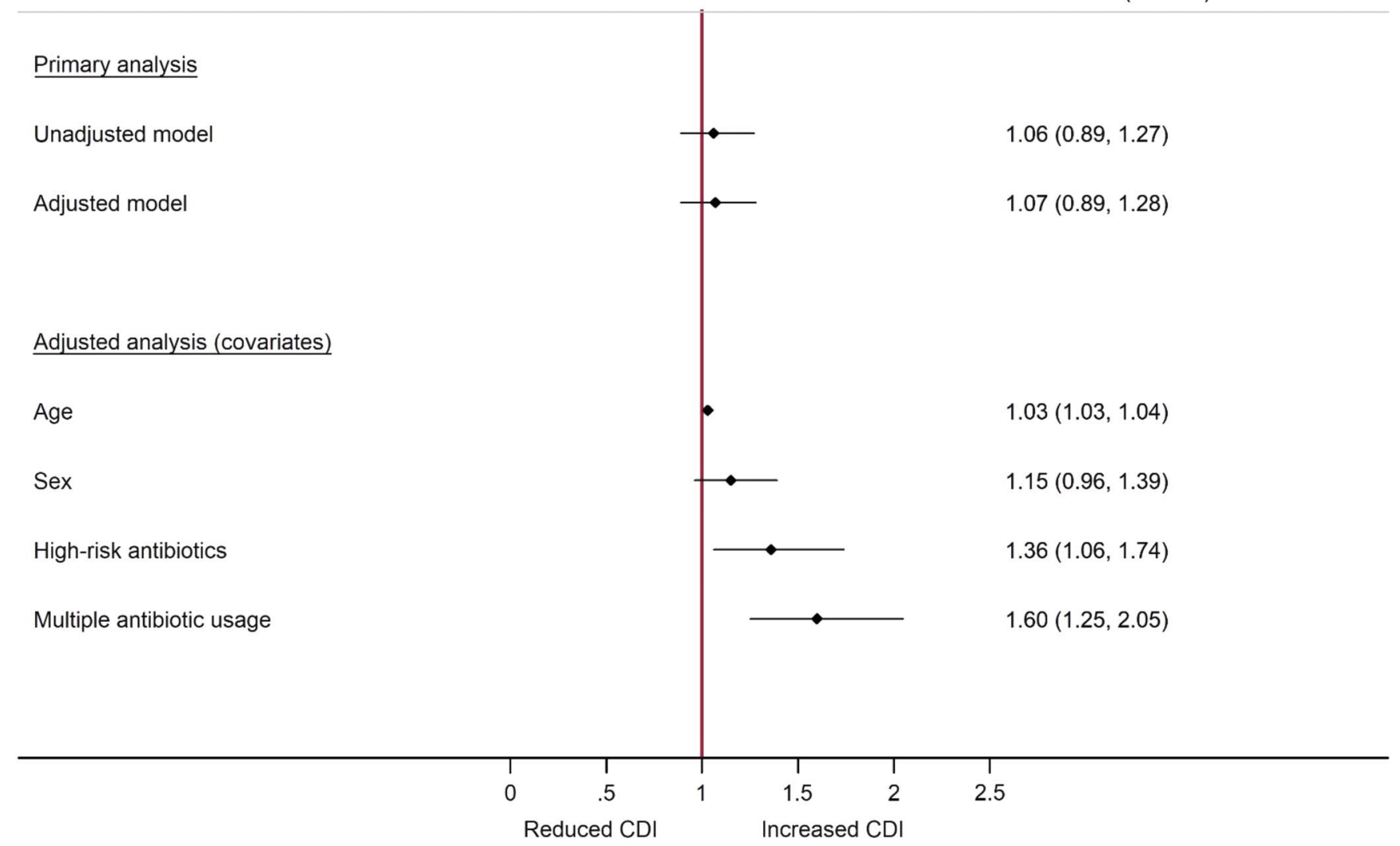

Legend. Forest plot for unadjusted and adjusted analyses for serious adverse events. $\mathrm{Cl}=\mathrm{Confidence} \mathrm{Interval}$.

FIGURE 3. Incidence of serious adverse events.

TABLE 3. Summary of Findings Table Based on Adjusted Analysis ${ }^{a}$

\begin{tabular}{|c|c|c|c|c|c|}
\hline & & & $\begin{array}{l}\text { Control } \\
\text { Group }\end{array}$ & $\begin{array}{l}\text { Probiotic } \\
\text { Group }\end{array}$ & \\
\hline Outcomes & $\begin{array}{c}\text { No. of } \\
\text { Participants } \\
\text { (No. of Studies) }\end{array}$ & $\begin{array}{c}\text { Relative Effect, } \\
\text { Odds Ratio } \\
(95 \% \text { CI })\end{array}$ & $\begin{array}{c}\text { Assumed } \\
\text { Risk per } \\
1,000^{\mathrm{b}}\end{array}$ & $\begin{array}{c}\text { Comparative } \\
\text { Risk } \\
\text { per } 1,000 \\
(95 \% \mathrm{CI})^{\mathrm{b}}\end{array}$ & $\begin{array}{l}\text { Quality of } \\
\text { Evidence } \\
\text { (GRADE) }^{\mathrm{c}}\end{array}$ \\
\hline
\end{tabular}

NOTE. CI, confidence interval; OR, odds ratio; GRADE, working group grades of evidence; CDI, Clostridium difficile infection; SAE, severe adverse event; IPD, individual participant data; RCT, randomized controlled trial.

${ }^{a}$ Patient or population: adults and children exposed to antibiotics. Settings: inpatient and outpatient. Intervention: probiotics.

${ }^{\mathrm{b}}$ Risk for the control group represents mean rate across studies. Risk for probiotics group is calculated by applying the relative effect rate to the control risk.

${ }^{c}$ High quality: further research is very unlikely to change our certainty in the estimate of effect. Moderate quality: further research is likely to have an important impact on our certainty in the estimate of effect and may change the estimate. Low quality: further research is very likely to have an important impact on our certainty in the estimate of effect and is likely to change the estimate. Very low quality: we are very uncertain about the estimate.

${ }^{\mathrm{d}}$ We rated CDI down for imprecision because of a low number of total events $(<300)$.

${ }^{e}$ We rated SAEs down for risk of publication bias as we were only able to obtain IPD for 18 of 32 RCTs and among the IPD trials only 11 trials $(\mathrm{n}=4,718)$ could be included in our adjusted analysis.

find a dose effect may represent the variability in dose administered (viable organisms per capsule) as well as the potential variability between studies with respect to whether the consumed dose survived gastric passage (viable organisms arriving in small and subsequently large bowel). Both are important areas of inquiry for future studies. 
Our study has several strengths. First, we used a comprehensive search; we had a high response rate from study authors ${ }^{52}$; and we were able to obtain 18 of 32 trials, including the 2 of the largest trials to date, ${ }^{41,44}$ one of which enrolled almost 3,000 participants. ${ }^{41}$ Our unadjusted effect estimates across primary and secondary outcomes were similar to studies for which we did not have IPD available, making the presence of a selection bias unlikely. Our analyses were robust to sensitivity analyses using different analytic methods, including categorization of age, aggregate-data meta-analyses, GEE analysis, and missing participant outcome data.

Several limitations must be emphasized. First, data for adjusted models were not available in $\sim 25 \%$ of participants. However, as the estimates were similar for the unadjusted model and adjusted IPD model, and the aggregate-data meta-analysis, this is unlikely to have introduced a significant bias. Second, data were too limited to allow an examination of each class of antibiotic separately; thus, we categorized antibiotics as high risk versus not high risk. ${ }^{53}$ For the same reason, we were unable to follow our a priori protocol to adjust for other potentially important confounding factors such as length of antibiotic exposure and length of hospitalization stay. Third, missing participant outcome data was a common issue across trials. Our multiple imputation analysis, however, suggested that outcomes were similar for participants with and without missing data. The incidence of CDI may be underestimated, given that 71 of 760 participants (9\%) with diarrhea were not tested for CDI. This affected participants in the intervention and control groups equally; thus, it is unlikely to have biased the results.

Moderate quality (ie, certainty) evidence suggests that probiotic prophylaxis is a useful CDI prevention strategy, particularly among participants taking 2 or more antibiotics and in hospital settings where the risk of CDI is $\geq 5 \%$. There was no evidence for concern regarding serious adverse events related to the preparations evaluated. Patients may value the absolute risk reduction $(1.0 \%$; NNT, 96$)$ we found, specifically among those probiotics with the largest body of evidence for efficacy and safety. The observation that probiotic prophylaxis is of greater benefit in populations with a moderate-to-high baseline risk should inform site selection in future studies, as should the use of probiotics in clinical settings.

\section{ACKNOWLEDGMENTS}

Financial support: No financial support was provided relevant to this article. Potential conflicts of interest: S.J.A. reports other support from Cultech Ltd, United Kingdom, grants and other from Yakult, United Kingdom, and personal fees from Astellas Pharma, outside the submitted work. H.S. reports grants from Arla and Biogaia, personal fees from Biogaia, Biocodex, Danone/ Nutricia, Hipp, Nestle, Nestle Nutrition Institute, Sequoia, and Yakult, as well as nonfinancial support from Dicofarm and Sequoia, outside the submitted work. M.M. is an employee at BioMerieux. C.P.S. reports unrestricted grants from Ferring Pharmaceuticals during the conduct of the study as well as grants and personal fees from Warner Chilcott, grants and personal fees from Abbvie, personal fees from Dr Falk, Takeda, and M.A.S., outside the submitted work. B.C.J. reports a grant from BioK + International for work outside the submitted work. All other authors report no conflicts of interest relevant to this article.
Address correspondence to Bradley C. Johnston, PhD, Department of Community Health and Epidemiology, Faculty of Medicine, Dalhousie University, Centre for Clinical Research, Room 404, 5790 University Avenue, Halifax, Nova Scotia, Canada, B3H 1V7 (bjohnston@dal.ca).

\section{SUPPLEMENTARY MATERIAL}

To view supplementary material for this article, please visit https://doi.org/10.1017/ice.2018.84.

\section{REFERENCES}

1. Dubberke ER, Olsen MA. Burden of Clostridium difficile on the healthcare system. Clin Infect Dis 2012;55(Suppl 2):S88-S92.

2. Freeman J, Bauer MP, Baines SD, et al. The changing epidemiology of Clostridium difficile infections. Clin Microbiol Rev 2010;23:529-549.

3. Dubberke ER, Butler AM, Reske KA, et al. Attributable outcomes of endemic Clostridium difficile-associated disease in nonsurgical patients. Emerg Infect Dis 2008;14:1031-1038.

4. Johnson S. Recurrent Clostridium difficile infection: a review of risk factors, treatments, and outcomes. J Infect 2009;58:403-410.

5. Lessa FC, Mu Y, Bamberg WM, et al. Burden of Clostridium difficile infection in the United States. N Engl J Med 2015;372:825-834.

6. Slimings C, Riley TV. Antibiotics and hospital-acquired Clostridium difficile infection: update of systematic review and meta-analysis. J Antimicrob Chemother 2014;69:881-891.

7. Bauer MP, Notermans DW, Van Benthem BH, et al. Clostridium difficile infection in Europe: a hospital-based survey. Lancet 2011;377(9759):63-73.

8. Lessa FC, Gould CV, McDonald LC. Current status of Clostridium difficile infection epidemiology. Clin Infect Dis 2012;55 (Suppl 2):S65-S70.

9. Louie TJ, Miller MA, Crook DW, et al. Effect of age on treatment outcomes in Clostridium difficile infection. J Am Geriatr Soc 2013;61:222-230.

10. Vesteinsdottir I, Gudlaugsdottir S, Einarsdottir R, Kalaitzakis E, Sigurdardottir O, Bjornsson ES. Risk factors for Clostridium difficile toxin-positive diarrhea: a population-based prospective casecontrol study. Eur J Clin Microbiol Infect Dis 2012;31:2601-2610.

11. Hill C, Guarner F, Reid G, et al. Expert consensus document: The International Scientific Association for Probiotics and Prebiotics consensus statement on the scope and appropriate use of the term probiotic. Nat Rev Gastroenterol Hepatol 2014;11:506-514.

12. Goldenberg JZ, Ma SS, Saxton JD, et al. Probiotics for the prevention of Clostridium difficile associated diarrhea in adults and children. Cochrane Database Syst Rev 2013;5:CD006095. doi: 10.1002/14651858.CD006095.pub3.

13. Goldenberg JZ, Yap C, Lytvyn L, Lo CK, Beardsley J, Mertz D, Johnston BC. Probiotics for the prevention of Clostridium difficile associated diarrhea in adults and children. Cochrane Database Syst Rev 2017:12:CD006095.

14. Lytvyn L, Mertz D, Sadeghirad B, Alaklobi F, Selva A, Alonso-Coello P, Johnston BC. Prevention of Clostridium difficile infection: a systematic survey of clinical practice guidelines. Infect Control Hosp Epidemiol 2016;37:901-908.

15. Carrico R, Bryant K, Lessa F, et al. Guide to preventing Clostridium difficile infections. Association for Professionals in Infection Control and Epidemiology website. http://apic.org/ 
Resource_/EliminationGuideForm/e3a85b7e-7ad8-4ab6-989254aef516cf10/File/2013CDiffFinal.pdf. Published 2013. Accessed August 14, 2017.

16. Dubberke ER, Carling P, Carrico R, et al. Strategies to prevent Clostridium difficile infections in acute-care hospitals: 2014 update. Infect Control Hosp Epidemiol 2014;35:628-645.

17. Surawicz CM, Brandt LJ, Binion DG, et al. Guidelines for diagnosis, treatment, and prevention of Clostridium difficile infections. Am J Gastroenterol 2013;108:478-498.

18. Vonberg RP, Kuijper E, Wilcox M, et al. Infection control measures to limit the spread of Clostridium difficile. Clin Microbiol Infect 2008;14(s5):2-20.

19. Hawkey P, Bain L, Borriello P, et al. Clostridium difficile infection: how to deal with the problem. London: Public Health England and Department of Health; 2008.

20. Debast S, Bauer M, Kuijper E. European Society of Clinical Microbiology and Infectious Diseases: update of the treatment guidance document for Clostridium difficile infection. Clin Microbiol Infect 2014;20(s2):1-26.

21. Lytvyn L, Mertz D, Thabane L, et al. Probiotics for the prevention of Clostridium difficile infection in adults and children: an individual patient data meta-analysis. PROSPERO: International prospective register of systematic reviews. Master's thesis, McMaster University. 2015. doi: 10.15124/CRD42015015701.

22. Bartlett JG, Gerding DN. Clinical recognition and diagnosis of Clostridium difficile Infection. Clin Infect Dis 2008;46(Suppl 1): S12-S18.

23. Higgins J, Altman DG, Gøtzsche PC, et al. The Cochrane Collaboration's tool for assessing risk of bias in randomised trials. BMJ 2011:343.

24. Guyatt GH, Oxman AD, Vist GE, et al. GRADE: an emerging consensus on rating quality of evidence and strength of recommendations. BMJ 2008;336(7650):924-926.

25. Egger M, Smith GD, Schneider M, Minder C. Bias in metaanalysis detected by a simple, graphical test. BMJ 1997;315 (7109):629-634.

26. Deeks JJ, Higgins J, Altman DG. Analysing data and undertaking meta-analyses. In: The Cochrane Handbook for Systematic Reviews of Interventions: Cochrane Book Series. Chichester, UK: Wiley \& Sons; 2008. Pp. 243-296.

27. Johnston BC, Goldenberg JZ, Vandvik PO, Sun X, Guyatt GH. Probiotics for the prevention of pediatric antibiotic-associated diarrhea. Cochrane Database Syst Rev 2011;9(11).

28. Gerding DN, Olson MM, Peterson LR, et al. Clostridium difficile -associated diarrhea and colitis in adults: a prospective casecontrolled epidemiologic study. Arch Intern Med 1986;146: 95-100.

29. Gao XW, Mubasher M, Fang CY, Reifer C, Miller LE. Dose-response efficacy of a proprietary probiotic formula of Lactobacillus acidophilus CL1285 and Lactobacillus casei LBC80R for antibiotic-associated diarrhea and Clostridium difficile-associated diarrhea prophylaxis in adult patients. Am J Gastroenterol 2010;105:1636-1641.

30. Duman DG, Bor S, Özütemiz Ö, et al. Efficacy and safety of Saccharomyces boulardii in prevention of antibiotic-associated diarrhoea due to Helicobacter pylori eradication. Eur J Gastroenterol Hepatol 2005;17:1357-1361.

31. Bravo MV, Bunout D, Leiva L, et al. Effect of probiotic Saccharomyces boulardii on prevention of antibiotic-associated diarrhea in adult outpatients with amoxicillin treatment. [In Spanish.] Revista Medica de Chile 2008;136:981-988.

32. Kotowska M, Albrecht P, Szajewska H. Saccharomyces boulardii in the prevention of antibiotic-associated diarrhoea in children: a randomized double-blind placebo-controlled trial. Aliment Pharmacol Ther 2005;21:583-590.

33. Pozzoni P, Riva A, Bellatorre AG, et al. Saccharomyces boulardii for the prevention of antibiotic-associated diarrhea in adult hospitalized patients: a single-center, randomized, double-blind, placebo-controlled trial. Am J Gastroenterol 2012;107:922-931.

34. Hickson M, D'Souza AL, Muthu N, et al. Use of probiotic Lactobacillus preparation to prevent diarrhoea associated with antibiotics: randomised double blind placebo-controlled trial. BMJ 2007;335(7610):80.

35. Klarin B, Wullt M, Palmquist I, Molin G, Larsson A, Jeppsson B. Lactobacillus plantarum 299v reduces colonisation of Clostridium difficile in critically ill patients treated with antibiotics. Acta Anaesthesiol Scand 2008;52:1096-1102.

36. Miller M. Results of 2 prospective randomized studies of Lactobacillus GG to prevent $C$. difficile infection in hospitalized adults receiving antibiotics; 2008a.

37. Miller M. Results of 2 prospective randomized studies of Lactobacillus GG to prevent $C$. difficile infection in hospitalized adults receiving antibiotics; 2008b.

38. Plummer S, Weaver MA, Harris JC, Dee P, Hunter J. Clostridium difficile pilot study: effects of probiotic supplementation on the incidence of C. difficile diarrhoea. Int Microbiol 2010;7: 59-62.

39. Psaradellis E, Sampalis J, Rampakakis E. Efficacy of BIO K+ CL1285 ${ }^{\circledR}$ in the reduction of antibiotic associated diarrhea-a placebo controlled double-blind randomized, multi-center study. Arch Med Sci 2010;6:56-64.

40. Selinger C, Bell A, Cairns A, Lockett M, Sebastian S, Haslam N. Probiotic VSL\# 3 prevents antibiotic-associated diarrhoea in a double-blind, randomized, placebo-controlled clinical trial. J Hosp Infect 2013;84:159-165.

41. Allen SJ, Wareham K, Wang D, et al. Lactobacilli and bifidobacteria in the prevention of antibiotic-associated diarrhoea and Clostridium difficile diarrhoea in older inpatients (PLACIDE): a randomised, double-blind, placebo-controlled, multicentre trial. Lancet 2013;382(9900):1249-1257.

42. Wong S, Jamous A, O'Driscoll J, et al. A Lactobacillus casei Shirota probiotic drink reduces antibiotic-associated diarrhoea in patients with spinal cord injuries: a randomised controlled trial. Brit J Nutr 2013;111:672-678.

43. Georgieva M, Pancheva R, Rasheva N, Usheva N, Ivanova L, Koleva K. Use of the probiotic Lactobacillus reuteri DSM 17938 in the prevention of antibiotic-associated infections in hospitalized Bulgarian children: a randomized controlled trial. J IMAB Annual Proceeding (Scientific Papers) 2015;21(4):895-900.

44. Ehrhardt S, Guo N, Hinz R, et al. Saccharomyces boulardii to prevent antibiotic-associated diarrhea: randomized, double-masked, placebo-controlled trial. Open Forum Infect Dis 2016;3(1):ofw011.

45. Lönnermark E, Friman V, Lappas G, Sandberg T, Berggren A, Adlerberth I. Intake of Lactobacillus plantarum reduces certain gastrointestinal symptoms during treatment with antibiotics. J Clin Gastroenterol 2010;44:106-112.

46. Ruszczyński M, Radzikowski A, Szajewska H. Clinical trial: effectiveness of Lactobacillus rhamnosus (strains E/N, Oxy and 
Pen) in the prevention of antibiotic-associated diarrhoea in children. Aliment Pharmacol Ther 2008;28:154-161.

47. Hempel S, Newberry S, Ruelaz A, et al. Safety of probiotics to reduce risk and prevent or treat disease. Evid Rep Technol Assess (Full Rep). 2011:1-645.

48. Colli A, Pozzoni P, Conte D, Casazza G. Response to Kolber et al. Am J Gastroenterol 2014;109:1082-1083.

49. Brown KA, Fisman DN, Moineddin R, Daneman N. The magnitude and duration of Clostridium difficile infection risk associated with antibiotic therapy: a hospital cohort study. PLoS One 2014;9:e105454.
50. Szajewska H. Pooling data on different probiotics is not appropriate to assess the efficacy of probiotics. Eur J Pediatr 2014;173:975.

51. Zawistowska-Rojek A, Zareba T, Mrówka A, Tyski S. Assessment of the microbiological status of probiotic products. Pol J Microbiol 2016;65:97-104.

52. Thomas D, Radji S, Benedetti A. Systematic review of methods for individual patient data meta-analysis with binary outcomes. $B M C$ Med Res Method 2014;14:79.

53. Brown K, Valenta K, Fisman D, Simor A, Daneman N. Hospital ward antibiotic prescribing and the risks of Clostridium difficile infection. JAMA Intern Med 2015;175:626-633. 